\title{
Testosterone: Bad for Men, Good for Women?
}

\author{
E. E. van der Wall
}

Published online: 16 December 2010

(C) The Author(s) 2010. This article is published with open access at Springerlink.com

Generally, high testosterone levels within the physiological range are associated with a more favourable cardiometabolic profile. Although the FDA has approved testosterone for use only in men with hypogonadism, whose sex glands produce extremely low amounts of testosterone, off-label use has dramatically increased in recent years. In the past two decades, there has been a huge increase in testosterone prescriptions, and many trials have shown benefit in terms of risk factor modification and symptoms. These observations fit also into the picture that reduced testosterone levels in men are associated with increased cardiovascular risk inducing elevated triglyceride levels, low high-density lipoprotein (HDL) cholesterol levels, central obesity, glucose intolerance, and diabetes. This has recently been demonstrated by Malkin et al. (October 26 issue, 2010, Heart), who showed that low testosterone levels (total testosterone $<8.1 \mathrm{nmol} / \mathrm{l}$ ) are associated with early death in men with heart disease. The longitudinal follow-up study involved 930 men with coronary heart disease for a period of about 7 years. During the study period, 41 of 194 (21\%) men with low testosterone levels died compared with 88 of $736(12 \%)$ men with normal levels of the hormone $(p=0.002)$. It was concluded that, if androgen deficiency is part of the underlying pathophysiology of atherosclerotic disease in men, the serum testosterone level could be viewed as a favourable modifiable risk factor.

However, this view has been challenged by Basaria et al. (July 8 issue, 2010, $N$ Engl $\mathrm{J} \mathrm{Med}$ ), who reported that

E. E. van der Wall $(\bowtie)$

Department of Cardiology, Leiden University Medical Center, P.O. Box 9600, Leiden, the Netherlands

e-mail: e.e.van_der_wall@lumc.nl testosterone is an adverse risk factor for cardiovascular disease (TOM trial: Testosterone in Older men with Mobility limitations). The authors showed that more than $20 \%$ of men aged 65 and older using testosterone developed serious cardiovascular problems. The study included 209 men, who were randomised to placebo or $100 \mathrm{mg}$ testosterone gel once daily for 6 months. Men on testosterone demonstrated increased strength in leg-press and chest-press strength and in stair climbing while carrying a load. However, among the 106 men using testosterone gel, 23 (22\%) had cardiovascular-related events compared with only 5 of $103(5 \%)$ men of the placebo group. Compared with the placebo group, men taking testosterone had a significant increase in haemoglobin and haematocrit levels, and a significant decrease in HDL cholesterol and LDL cholesterol levels. Because of the unexpected high rate of adverse cardiac events, the study was acutely discontinued.

While current discussions did mainly focus on the role of testosterone and cardiovascular disease in men, the relationship between testosterone and cardiovascular diseases may be gender-specific [1-5]. According to a recent study by Lellamo et al. (October 12 issue, 2010, J Am Coll Cardiol), application of testosterone may benefit women with heart failure. Women with systolic heart failure on low-dose testosterone ( $300 \mu \mathrm{g} / \mathrm{twice}$ daily) for 6 months, on top of standard medical therapy, showed significant gains in exercise and ventilatory capacity and large-muscle strength along with heightened insulin sensitivity. Testosterone was applied to 36 elderly women through transdermal patches at a much lower dosage than are used for testosterone supplementation in men and produced no apparent androgenic or other untoward effects. As a result, testosterone seems to be an effective and safe therapy for elderly women with congestive heart failure. 
To summarise, there are conflicting results on the effects of testosterone on the cardiovascular system. The role of testosterone in male cardiovascular health is still not completely understood as both reduced and increased levels may result in cardiovascular-related complications. Apart from that, testosterone may have differential effects in men and women. Interestingly, application of testosterone seems to be disadvantageous in men, but beneficial in women. Many more additional studies are therefore needed to explain the effect of testosterone on the development of atherosclerosis. In particular, the gender-specific effects of testosterone should be thoroughly evaluated.

Open Access This article is distributed under the terms of the Creative Commons Attribution Noncommercial License which per- mits any noncommercial use, distribution, and reproduction in any medium, provided the original author(s) and source are credited.

\section{References}

1. Maas AH, van't Hof AW, de Boer MJ. Cardiovascular risk in women after metabolic complications in pregnancy. Neth Heart J. 2007;15:415-7.

2. Engelfriet P, Mulder BJ. Gender differences in adult congenital heart disease. Neth Heart J. 2009;17:414-7.

3. Maas AH, Franke HR. Women's health in menopause with a focus on hypertension. Neth Heart J. 2009;17:68-72.

4. van der Wall EE. GENDER issues: media news value? Neth Heart J. 2010;18:343.

5. Maas AH, Appelman YE. Gender differences in coronary heart disease. Neth Heart J. 2010;18:598-602. 